\title{
Does morbid obesity influence perioperative outcomes after video-assisted thoracic surgery (VATS) lobectomy for non-small cell lung cancer? Analysis of the Italian VATS group registry
}

\author{
Francesco Guerrera ${ }^{1,2,6} \oplus$ - Paraskevas Lyberis ${ }^{2} \cdot$ Paolo Olivo Lausi $^{1,2} \cdot$ Riccardo Carlo Cristofori $^{2} \cdot$ Roberto Giobbe $^{2}$. \\ Massimo Molinatti ${ }^{2} \cdot$ Pier Luigi Filosso ${ }^{1,2} \cdot$ Carlo Curcio $^{3} \cdot$ Roberto Crisci $^{4,5} \cdot$ Enrico Ruffini $^{1,2} \cdot$ on the behalf of the \\ Italian VATS Group
}

Received: 25 March 2021 / Accepted: 7 August 2021 / Published online: 16 August 2021

(c) The Author(s) 2021

\begin{abstract}
Objectives Obesity in Europe, and worldwide, has been an increasing epidemic during the past decades. Moreover, obesity has important implications regarding technical issues and the risks associated with surgical interventions. Nevertheless, there is a lack of evidence assessing the influence of obesity on video-assisted thoracic surgery (VATS) lobectomy results. Our study aimed to assess the impact of morbid obesity on perioperative clinical and oncological outcomes after VATS lobectomy using a prospectively maintained nationwide registry.

Methods The Italian VATS lobectomy Registry was used to collect all consecutive cases from 55 Institutions. Explored outcome parameters were conversion to thoracotomy rates, complication rates, intra-operative blood loss, surgical time, hospital postoperative length of stay, chest tube duration, number of harvested lymph-node, and surgical margin positivity. Results From 2016 to 2019, a total of 4412 patients were collected. 74 patients present morbid obesity (1.7\%). Multivariableadjusted analysis showed that morbid obesity was associated with a higher rate of complications (32.8\% vs $20.3 \%)$, but it was not associated with a higher rate of conversion, and surgical margin positivity rates. Moreover, morbid obesity patients benefit from an equivalent surgical time, lymph-node retrieval, intraoperative blood loss, hospital postoperative length of stay, and chest tube duration than non-morbid obese patients. The most frequent postoperative complications in morbidly obese patients were pulmonary-related (35\%).

Conclusion Our results showed that VATS lobectomy could be safely and satisfactorily conducted even in morbidly obese patients, without an increase in conversion rate, blood loss, surgical time, hospital postoperative length of stay, and chest tube duration. Moreover, short-term oncological outcomes were preserved.
\end{abstract}

Keywords Obesity $\cdot$ Lobectomy $\cdot$ Video-assisted thoracic surgery $\cdot$ Morbidity $\cdot$ Mortality $\cdot$ Lung Cancer

Obesity in Europe, and worldwide, has been an increasing epidemic during the past decades $[1,2]$. In particular, in

The members of VATS group are listed in the acknowledgements section.

Francesco Guerrera

francesco.guerrera@unito.it

1 Department of Surgical Science, University of Torino, Torino, Italy

2 Department of Thoracic Surgery, Azienda Ospedaliera Universitaria Città della Salute e della Scienza di Torino, Torino, Italy
Italy, the obesity rate augments from $6 \%$ in 1991 to $10 \%$ in 2018 [3].

Increasing obesity incidence represents a noteworthy health problem, particularly considering that it is associated with the risk of developing chronic diseases such as

3 Department of Thoracic Surgery, Monaldi Hospital, Napoli, Italy

4 Department of Thoracic Surgery, University of L'Aquila, L'Aquila, Italy

5 Thoracic Surgery Unit, “G. Mazzini” Hospital, Teramo, Italy

6 Corso Dogliotti, 14, 10126 Torino, Italy 
cardiovascular disease, musculoskeletal disorders, type 2 diabetes, hypertension, coronary heart disease, sleep apnea, and kidney failure $[2,4,5]$ in addition to a generally decreased life expectancy, principally in the young adult population [6-8]. Moreover, all these conditions could increase the risk of postoperative surgical complications, with mutual boost effects $[9,10]$. Additionally, obesity itself has important implications regarding technical issues during the surgical procedure $[11,12]$.

In the literature, there is emerging evidence on relationship between higher BMI and lung cancer [13]. Indeed, the ratio of overweight and obese patients with lung cancer who present for major pulmonary resection for NSCLC incessantly raised during the last decades [14].

In order to increase perioperative outcomes and decrease postoperative complications, minimally invasive thoracic surgical procedures [i.e., video-assisted thoracic surgery (VATS) lobectomy] have been largely adopted worldwide, in alternative to classic open surgery via thoracotomy [14]. Recently, the results of a UK multicentric VIOLET randomized controlled trial showed a relationship between VATS lobectomy and enhanced postoperative clinical outcome [15]. However, there is a lack of evidence assessing the influence of morbid obesity on VATS lobectomy results.

The aim of our study was to assess the impact of morbid obesity (Body Mass Index $\geq 40$ ) on perioperative clinical and oncological outcomes after VATS lobectomy using a prospectively maintained nationwide registry, the Italian VATS group registry [16].

\section{Methods}

From 2016 to 2019, out of a total of 4972 patients submitted to thoracoscopic major lung resection by 55 centers of the Italian VATS Group database, 4412 patients submitted to VATS lobectomy for lung cancer were included in the present study. Patients submitted to VATS segmentectomy, bilobectomy, or pneumonectomy were excluded. Informed consent was obtained from all individual participants included in the study.

Primary outcomes explored were conversion to thoracotomy rates and complication rates (Grade $\geq 2$ according to the Clavien-Dindo classification [17]). An additional analysis on primary endpoints was performed stratifying patients according to BMI as follows: $\leq 30,30-40, \geq 40$.

As secondary outcomes, surgical margin positivity rates, intra-operative blood loss, surgical time, hospital postoperative length of stay, chest tube duration, and the number of harvested lymph-node were assessed.

\section{Statistical analysis}

Baseline patient characteristics are summarized by number and percentages, or median and interquartile range (IQR), as appropriate. Between-group differences were evaluated by Wilcoxon-Mann-Whitney test (continuous variables) or $\chi^{2}$ test or Fisher's exact test (categorical variables), as appropriate.

Univariable and multivariable-adjusted logistic regression models were used to evaluate categorical outcomes, while different continuous outcomes were compared by the Wilcoxon-Mann-Whitney test. The variables in the adjusted models were age, gender, smoking history, CCI, ECOG performance status, FEV1\%, DLCO\%, surgeon experience, $\mathrm{pT}$ stage, $\mathrm{pN}$ stage, preoperative diagnosis, and performed adhesiolysis.

All statistical tests were two-sided and $P$ values of 0.05 or less were considered statistically significant. Data analysis was performed using Stata software version 15.1 (Stata-Corp, College Station, Texas).

\section{Results}

Median BMI in the present cohort was 25.8 (IQR 23.4-28.7) (Table 1). Most of the patients present a BMI $<40$ (4338-98.3\%), while out of 74 patients were morbidly obese (BMI $\geq 40$ ). Most patients were male (2681-60.7\%) and the mean age at the time of surgery was 69 years (IQR 62-75). 425 (9.6\%) cases of conversion to thoracotomy were observed in the whole population. Median surgical time was $174 \mathrm{~min}$ (IQR 135-210), the median number of harvested lymph-nodes was 11 (IQR 7-16), median intraoperative blood loss $100 \mathrm{ml}$ (IQR 50-200), median chest drain duration 4 days (IQR 3-5), and median postoperative length of stay 5 days (IQR 4-7). In the whole cohort, 906 (20.5\%) complications and 100 (2.3\%) surgical margin positivity cases were observed (Table 2).

At the univariable analysis, the Morbid obesity group showed a significant higher post-operative morbidity rate (26 vs $880-35.1 \%$ vs 20.3\%) [Odds Ratio (OR) 2.13, 95\% C.I. $1.31-3.45, P=0.002)$. The most frequent postoperative complications in morbidly obese patients were pulmonary-related (9-35\%): 3 persistent pleural effusion/ empyema, 2 prolonged air leak ( $>7$ days), 2 prolonged mechanical ventilation, 1 pulmonary embolism, 1 atelectasis. Morbid obesity was not associated with a higher rate of conversion (10 vs 415-13.5\% vs 9.6\%) (OR $1.48,95 \%$ C.I. $0.75-2.90, P=0.26)$ and surgical margin positivity rates (1 vs $99-1.4 \%$ vs $2.4 \%$ ) (OR $0.58,95 \%$ 
Table 1 Baseline characteristics in the overall population

\begin{tabular}{|c|c|}
\hline Factor & $\begin{array}{l}\text { All } \\
n=4412\end{array}$ \\
\hline \multicolumn{2}{|l|}{ BMI, $n(\%)$} \\
\hline Median $\left(\mathrm{IQR}^{\mathrm{a}}\right)$ & $25.8(23.4-28.7)$ \\
\hline$\geq 40$ & $74(1.7)$ \\
\hline$<40$ & $4338(98.3)$ \\
\hline Age (years), median (IQR) & $69(62-75)$ \\
\hline Gender (male), $n(\%)$ & $2681(60.7)$ \\
\hline Smoking history (ever), $n(\%)$ & $3137(71.1)$ \\
\hline CCI, median (IQR) & $3(3-4)$ \\
\hline ECOG, median (IQR) & $0(0-1)$ \\
\hline FEV1 (\%), median (IQR) & $93(80-106)$ \\
\hline DLCO (\%), median (IQR) & $83(71-95)$ \\
\hline Surgeon experience $^{\mathrm{b}}, n(\%)$ & $2676(60.7)$ \\
\hline \multicolumn{2}{|l|}{ cT stage, $n(\%)$} \\
\hline $\mathrm{cT} 1 \mathrm{a}-\mathrm{b}-\mathrm{c}$ & $2939(66.6)$ \\
\hline cT2a-b & $1067(24.2)$ \\
\hline cT3 & $322(7.3)$ \\
\hline cT4 & $83(1.8)$ \\
\hline \multicolumn{2}{|l|}{ cN stage, $n(\%)$} \\
\hline cNO & $3873(87.9)$ \\
\hline $\mathrm{cN} 1$ & $274(6.3)$ \\
\hline $\mathrm{cN} 2$ & $256(5.8)$ \\
\hline \multicolumn{2}{|l|}{ pT stage, $n(\%)$} \\
\hline pT1a-b-c & $2893(66.1)$ \\
\hline pT2a-b & $1054(24.1)$ \\
\hline pT3 & $336(7.6)$ \\
\hline pT4 & $97(2.2)$ \\
\hline \multicolumn{2}{|l|}{ pN stage, $n(\%)$} \\
\hline pNo & $3873(81.8)$ \\
\hline pN1 & $418(9.9)$ \\
\hline $\mathrm{pN} 2$ & $351(8.3)$ \\
\hline Preoperative diagnosis (yes), $n(\%)$ & $1900(43.1)$ \\
\hline Adhesiolysis (yes), $n(\%)$ & 1218 (27.6) \\
\hline
\end{tabular}

$B M I$ Body Mass Index, $C C I$ Charlson comorbidity index, ECOG Eastern Cooperative Oncology Group performance status

${ }^{a}$ Interquartile range

${ }^{\mathrm{b}}>50$ VATS lobectomy procedures performed

C.I. $0.080-4.23, P=0.59)$. Morbid obesity patients presented an equivalent surgical time (180 $\mathrm{min}$ vs $173 \mathrm{~min}$, $P=0.116$ ), lymph-node retrieval (9 vs $11, P=0.835$ ), intraoperative blood loss ( $100 \mathrm{ml}$ vs $100 \mathrm{ml}, P=0.554)$, chest tube duration ( 4 days vs 4 days, $P=0.969$ ), and hospital post-operative length of stay ( 5 days vs 5 days, $P=0.729$ ) than non-morbid obese patients (Figs. 1 and 2).

At the multivariable analyses (Table 3), Morbid obesity resulted to be an independent prognostic factor for postoperative morbidity rate (OR $2.74,95 \%$ C.I. $1.63-4.61$,
Table 2 Baseline characteristics: morbid obesity (BMI $\geq 40$ ) vs Nonmorbid obesity $(\mathrm{BMI}<40)$ groups

\begin{tabular}{|c|c|c|c|}
\hline Factor & $\begin{array}{l}\mathrm{BMI} \geq 40 \\
n=74\end{array}$ & $\begin{array}{l}\mathrm{BMI}<40 \\
n=4338\end{array}$ & $P$ \\
\hline Age (years), median $\left(\mathrm{IQR}^{\mathrm{a}}\right)$ & $68(59-63)$ & $69(63-75)$ & 0.089 \\
\hline Gender (male), $n(\%)$ & $40(54.1)$ & $2641(60.9)$ & 0.233 \\
\hline Smoking history (ever), $n(\%)$ & $50(67.6)$ & $3087(71.2)$ & 0.499 \\
\hline CCI, median (IQR) & $3(2-4)$ & $3(3-4)$ & 0.041 \\
\hline ECOG, median (IQR) & $0(0-1)$ & $0(0-1)$ & 0.835 \\
\hline FEV1 (\%), median (IQR) & $93(82-109)$ & $93(80-106)$ & 0.884 \\
\hline $\operatorname{DLCO}(\%)$, median (IQR) & $89(78-100)$ & $83(71-95)$ & 0.008 \\
\hline Surgeon experience ${ }^{\mathrm{b}}, n(\%)$ & $39(52)$ & $2637(60.8)$ & 0.099 \\
\hline cT stage, $n(\%)$ & & & 0.103 \\
\hline cT1a-b-c & $58(78.3)$ & $2881(66.4)$ & \\
\hline $\mathrm{cT} 2 \mathrm{a}-\mathrm{b}$ & $14(18.9)$ & $1053(24.3)$ & \\
\hline cT3 & $1(1.4)$ & $321(7.4)$ & \\
\hline cT4 & $1(1.4)$ & $82(1.9)$ & \\
\hline cN stage, $n(\%)$ & & & 0.683 \\
\hline $\mathrm{cNO}$ & $63(85.1)$ & $3810(87.9)$ & \\
\hline $\mathrm{cN} 1$ & $7(9.5)$ & $267(6.2)$ & \\
\hline $\mathrm{cN} 2$ & $4(5.4)$ & $343(5.9)$ & \\
\hline pT stage, $n(\%)$ & & & 0.063 \\
\hline pT1a-b-c & $57(77.0)$ & $2836(65.9)$ & \\
\hline pT2a-b & $14(18.9)$ & $1040(24.1)$ & \\
\hline pT3 & $1(1.4)$ & $335(7.8)$ & \\
\hline pT4 & $2(2.7)$ & $95(2.2)$ & \\
\hline pN stage, $n(\%)$ & & & 0.584 \\
\hline pNO & $55(77.4)$ & $3406(81.9)$ & \\
\hline $\mathrm{pN} 1$ & $8(11.3)$ & 410 & \\
\hline $\mathrm{pN} 2$ & $8(11.3)$ & $343(8.2)$ & \\
\hline $\begin{array}{l}\text { Preoperative diagnosis (yes), } n \\
(\%)\end{array}$ & $2469(56.9)$ & $43(58.1)$ & 0.837 \\
\hline Adhesiolysis (yes), $n(\%)$ & $3139(72.4)$ & $55(74.3)$ & 0.708 \\
\hline
\end{tabular}

$B M I$ Body Mass Index, CCI Charlson comorbidity index, ECOG Eastern Cooperative Oncology Group performance status

${ }^{\mathrm{a}}$ Interquartile range

b $>50$ VATS lobectomy procedures performed

$P<0.001)$. Morbid obesity was not associated with a higher rate of conversion (OR 1.63, 95\% C.I. $0.79,3.39, P=0.19$ ).

The additional multivariable analysis showed morbid obesity as independent prognostic factor for morbidity rate (BMI $\leq 30$ as reference; BMI $30-40$ OR 1.34, 95\% C.I. 0.87, $2.07, P=0.16 ; \geq 40$ OR $2.74,95 \%$ C.I. $1.63-4.59, P<0.001$ ), but not for conversion rates $(\mathrm{BMI} \leq 30$ as reference; $\mathrm{BMI}$ 


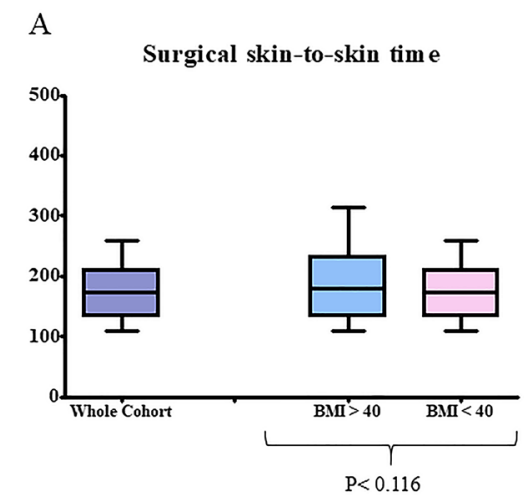

B

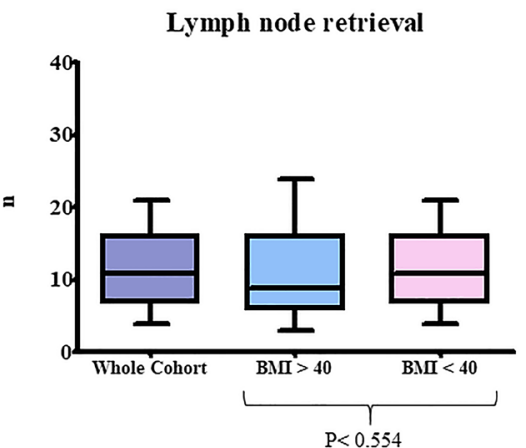

$\mathrm{C}$

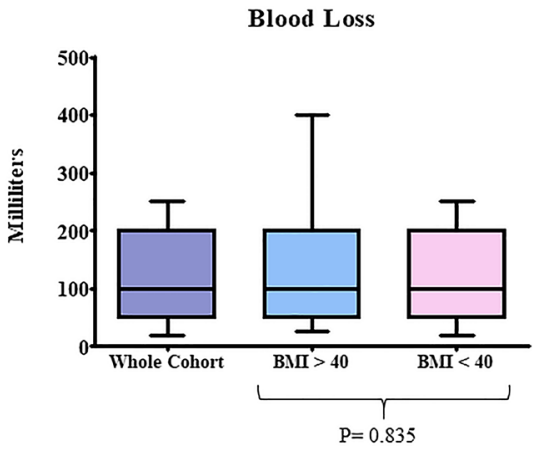

Fig. 1 Morbid obesity (BMI $\geq 40)$ Versus Non-morbid obesity (BMI < 40): Box-and-whisker plots illustrate the distribution of surgical time (A), lymph-node retrieval $(\mathbf{B})$, and blood loss $(\mathbf{C})$

Fig. 2 Morbid obesity (BMI $\geq 40$ ) Versus Non-morbid obesity $(\mathrm{BMI}<40)$ : Box-andwhisker plots illustrate the distribution of chest tube duration (A), hospital postoperative length of stay (B)

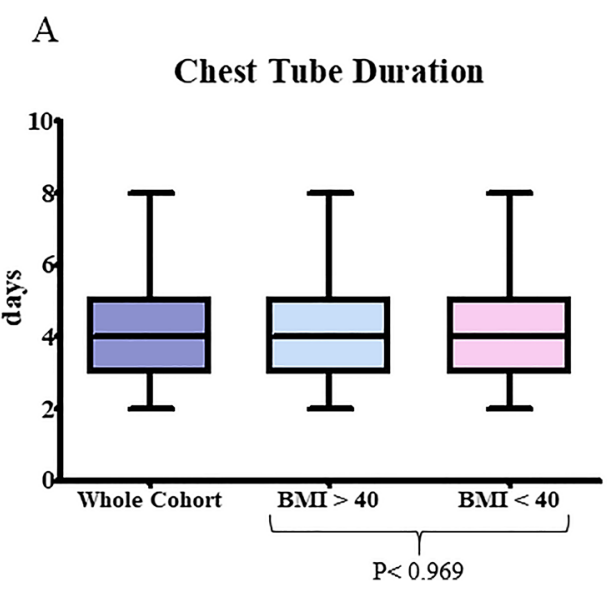

B

Hospital postoperative length of stay

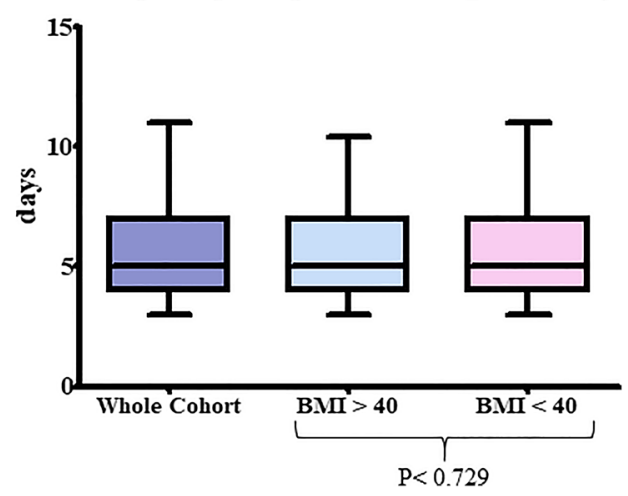

Table 3 Logistic regression models from primary endpoint: Morbid obesity (BMI $\geq 40)$ vs Non-morbid obesity $(\mathrm{BMI}<40)$ groups

\begin{tabular}{|c|c|c|c|c|c|c|}
\hline Factor & $\begin{array}{l}\mathrm{BMI} \geq 40 \\
n=74\end{array}$ & $\begin{array}{l}\mathrm{BMI}<40 \\
n=4338\end{array}$ & Univariable model & $P$ & Multivariable-adjusted model ${ }^{\mathrm{a}}$ & $P$ \\
\hline $\begin{array}{l}\text { Post-operative complications (yes), } n \\
\quad(\%)\end{array}$ & $26(35.1)$ & $880(20.3)$ & OR $2.13,95 \%$ C.I. $1.31-3.45$ & 0.002 & OR $2.74,95 \%$ C.I. $1.63-4.61$ & $<0.001$ \\
\hline Conversion to thoracotomy (yes), $n(\%)$ & $10(13.5)$ & $415(9.6)$ & OR $1.48,95 \%$ C.I. $0.75-2.90$ & 0.26 & OR $1.63,95 \%$ C.I. $0.79,3.39$ & 0.19 \\
\hline Surgical margin positivity (yes), $n(\%)$ & $1(1.4)$ & $99(2.4)$ & OR $0.58,95 \%$ C.I. $0.080-4.23$ & 0.59 & OR $0.67,95 \%$ C.I. $0.089,5.07$ & 0.70 \\
\hline
\end{tabular}

$B M I$ Body Mass Index

${ }^{a}$ Adjusted for age, gender, smoking history, CCI, ECOG performance status, FEV1\%, DLCO\%, surgeon experience, pT stage, pN stage, preoperative diagnosis, and performed adhesiolysis

30-40 OR 1.48, 95\% C.I. $0.86,2.56, P=0.16 ; \geq 40$ OR 1.59, $95 \%$ C.I. $0.77,3.27, P=0.21$ ).

\section{Discussion}

The minimally invasive surgical approaches have been established in order to increase perioperative outcomes and decrease postoperative complications, with respect to the standard open approaches.

Also, in thoracic surgery, these approaches [i.e., VATS and robotic-assisted thoracic surgery (RATS)] should be 
advisable especially in the high-risk surgical populations, like the elderly and obese ones [18]. Presumably, the ratio of patients with elevated BMI referred to thoracic surgical procedures will constantly increase in the next future [11, 14]. Consequently, it is mandatory to obtain a comprehensive insight into the effect of morbid obesity on perioperative outcomes in such patients [11, 14].

The results of the present study suggest that, in the cohort from the Italian VATS Group database,

(1) Morbid obesity was not associated with a higher rate of conversion and surgical margin positivity rates.

(2) Morbid obesity was associated with a higher rate of complications, in particular with the pulmonary-related one.

(3) Morbid obesity patients benefit from an equivalent surgical time, lymph-node retrieval, intraoperative blood loss, hospital postoperative length of stay, and chest tube duration than non-morbid obese patients.

Normally, patients with increased BMI are characterized by the presence of cardiovascular comorbidities, which could jeopardize hemodynamic stability. Similarly, obese patients present a decrease of residual capacity, augmented airway resistance, and a reduction of chest wall compliance, which may increase the risk of pulmonary complications [4, 19-22]. Furthermore, more than 40\% of obese patients had Obstructive Sleep Apnea Syndrome [23]. OSAS patients present the incapacity to maintain airway patency, with intermittent respiratory obstruction and intensification of respiratory efforts. Finally, drug metabolism could strongly differ between patients with normal and increased BMI; consequently, titration and careful dosing should be mandatory. For all these reasons, it could be intuitive that patients with elevated BMI developed more frequently post-operative complications. Nevertheless, the current literature presents contradictory results on this topic, and the "obesity paradox," namely the protective effect of obesity on complication incidence, has been observed also in the thoracic surgery cohort analysis [24-28]. On the other hand, several studies presented a higher incidence of complications (notably pulmonary ones) in obese patients submitted to thoracic surgery [12, 21, 29].

The foundation of the obesity paradox has not been clearly elucidated, but protective effect peripheral body fat and reduced inflammatory response are common assumptions reported in the literature [10]. Nevertheless, Childers and Allison [30] proposed a mathematical model (U-shaped curve) in order to explain this occurrence: the highest mortality was presented by severe BMI values (both morbid obesity and severe underweight), while overweight, light, or moderate obesity shown lower mortality rate. Indeed,
Tulinskýc et al. suppose that if the ratio of morbidly obese patients in their cohort was higher, the occurrence of complications would have been higher [28]. Coherently, in the present study, we focalize on morbidly obese patients. Our results showed that morbid obesity was associated with a higher rate of complications after VATS lobectomy, with a high rate of pulmonary-related complications. In particular, only $30 \%$ of the pulmonary complications observed in Morbid could be considered major one. Nevertheless, greater care and attention must be paid in the early recognition and treatment of this kind of morbidity, that this particularly related to obesity pathophysiology [5].

Interestingly, we did not find an association between morbid obesity and other perioperative clinical or technical outcomes, as the rate of conversion, surgical time, and surgical margin positivity rates, lymph-node retrieval, intraoperative blood loss, hospital postoperative length of stay, and chest tube duration. In particular, our findings are in contrast with St Julien et al. that investigated the database of the society of thoracic surgeons and observed an increased operating time by $7.2 \mathrm{~min}$ for every 10-unit increase in BMI [29]. On the other hand, our results were in line with a recent study on RATS lobectomy that demonstrated equivalence in surgical time between obese and non-obese patients [24].

The present study could be affected by several limitations, principally associated with a large multi-institutional dataset setting, and the retrospective nature of the research. Nevertheless, the major strength of our analysis is the use of a large, homogeneous, and prospectively maintained national scale patient cohort, as the one proved by the Italian VATS Group database. This fact permits the data reliability and, consequently, reinforces our conclusions.

To conclude, our findings showed that VATS lobectomy could be safely and satisfactorily conducted even in morbidly obese patients, without an increase in conversion rate, blood loss, surgical time, hospital postoperative length of stay, and chest tube duration. Moreover, short-term technical and oncological outcomes were preserved. Nevertheless, greater care and attention must be paid to the possible development of morbidity, and in particular pulmonary ones, in the postoperative period.

Acknowledgements Members of Italian VATS Group: Mancuso Maurizio (Azienda Ospedaliera Nazionale SS. Antonio e Biagio e C. Arrigo), Pernazza Fausto (Azienda Ospedaliera Nazionale SS. Antonio e Biagio e C. Arrigo), Refai Majed (Azienda Ospedaliero Universitaria Ospedali Riuniti di Ancona), Stella Franco (ASL Romagna, Forlì Hospital—Forlì-Department of Respiratory System and Chest Diseases), Argnani Desideria (ASL Romagna, Forlì Hospital—Forlì-Department of Respiratory System and Chest Diseases), Marulli Giuseppe (Policlinico di Bari, Ospedale Giovanni XXIII), De Palma Angela (Policlinico di Bari, Ospedale Giovanni XXIII), Bortolotti Luigi (Humanitas Gavazzeni), Rizzardi Giovanna (Humanitas Gavazzeni), Solli Piergiorgio (Policlinico S. Orsola-Malpighi), Dolci Giampiero (Policlinico S. Orsola-Malpighi), Perkmann Reinhold (Ospedale Centrale di 
Bolzano), Zaraca Francesco (Ospedale Centrale di Bolzano), Benvenuti Mauro Roberto (ASST Spedali Civili), Gavezzoli Diego (ASST Spedali Civili), Cherchi Roberto (AO Brotzu, Ospedale Oncologico Businco), Ferrari Paolo Albino (AO Brotzu, Ospedale Oncologico Businco), Mucilli Felice (Ospedale "Ss. Annunziata"), Camplese Pierpaolo (Ospedale "Ss. Annunziata"), Melloni Giulio (Azienda Ospedialiera Santa Croce e Carle), Mazza Federico (Azienda Ospedialiera Santa Croce e Carle), Cavallesco Giorgio (Arcispedale Sant'Anna), Maniscalco Pio (Arcispedale Sant'Anna), Voltolini Luca (Azienda Ospedaliara Universitaria Careggi), Gonfiotti Alessandro (Azienda Ospedaliara Universitaria Careggi), Sollitto Francesco (Ospedali Riuniti-Foggia-Cardio-thoracic and Vascular Department), Ardò Nicoletta Pia (Ospedali Riuniti-Foggia-Cardio-thoracic and Vascular Department), Pariscenti Gian Luca (Ospedale Policlinico San Martino), Risso Carlo (Ospedale Policlinico San Martino), Surrente Corrado (Ospedale Vito Fazzi), Lopez Camillo (Ospedale Vito Fazzi), Droghetti Andrea (Ospedale Carlo Poma), Giovanardi Michele (Ospedale Carlo Poma), Breda Cristiano (Ospedale dell'Angelo), Lo Giudice Fabio (Ospedale dell'Angelo), Alloisio Marco (Humanitas Rozzano)-Bottoni Edoardo (Humanitas Rozzano), Spaggiari Lorenzo (IEO-Istituto Europeo di Oncologia), Gasparri Roberto (IEO-Istituto Europeo di Oncologia), Torre Massimo (Ospedale Niguarda), Rinaldo Alessandro (Ospedale Niguarda), Nosotti Mario (Fondazione IRCCS Ca' Granda Ospedale Maggiore Policlinico), Tosi Davide (Fondazione IRCCS Ca' Granda Ospedale Maggiore Policlinico), Negri Giampeiro (Ospedale San Raffaele), Bandiera Alessandro (Ospedale San Raffaele), Baisi Alessandro (Ospedale San Paolo), Raveglia Federico (Ospedale San Paolo), Stefani Alessandro (Ospedale Policlinico di Modena), Natali Pamela (Ospedale Policlinico di Modena), Scarci Marco (Ospedale San Gerardo), Pirondini Emanuele (Ospedale San Gerardo), Curcio Carlo (Ospedale Monaldi), Amore Dario (Ospedale Monaldi), Rena Ottavio (Ospedale Maggiore della Carità), Nicotra Samuele (Policlinico Universitario), Dell'Amore Andrea (Policlinico Universitario), Bertani Alessandro (Istituto Mediterraneo per i Trapianti Ismett IRCCS), Tancredi Giorgia (Istituto Mediterraneo per i Trapianti Ismett IRCCS), Ampollini Luca (Policlinico Universitario di Parma), Carbognani Paolo (Policlinico Universitario di Parma), Puma Francesco (Ospedale Santa Maria della Misericordia), Vinci Damiano (Ospedale Santa Maria della Misericordia), Cardillo Giuseppe (Azienda Ospedaliera San Camillo-Forlanini), Carleo Francesco (Azienda Ospedaliera San Camillo-Forlanini), Margaritora Stefano (Fondazione Policlinico Universitario Agostino Gemelli IRCCS), Meacci Elisa (Fondazione Policlinico Universitario Agostino Gemelli IRCCS), Paladini Piero (Azienda Ospedaliero-Universitaria Senese), Ghisalberti Marco (Azienda Ospedaliero-Universitaria Senese), Crisci Roberto (Ospedale Giuseppe Mazzini), Divisi Duilio (Ospedale Giuseppe Mazzini), Fontana Diego (Ospedale San Giovanni Bosco), Della Beffa Vittorio (Ospedale San Giovanni Bosco), Morelli Angelo (Santa Maria della Misericordia), Londero Francesco (Santa Maria della Misericordia), Imperatori Andrea (Ospedale Di Circolo), Rotolo Nicola (Ospedale Di Circolo), Alberto (IRCCS Ospedale Sacro Cuore Don Calabria), Viti Andrea (IRCCS Ospedale Sacro Cuore Don Calabria), Infante Maurizio (Ospedale Borgo Trento), Benato Cristiano (Ospedale Borgo Trento).

Funding Open access funding provided by Università degli Studi di Torino within the CRUI-CARE Agreement.

\section{Declarations}

Disclosures Drs. Francesco Guerrera, Paraskevas Lyberis, Paolo Olivo Lausi, Riccardo Carlo Cristofori, Roberto Giobbe, Massimo Molinatti, Pier Luigi Filosso, Carlo Curcio, Roberto Crisci, and Enrico Ruffini have no conflicts of interest or financial ties to disclose.
Ethical approval All procedures performed in studies involving human participants were in accordance with the ethical standards of the institutional and/or national research committee and with the 1964 Helsinki declaration and its later amendments or comparable ethical standards.

Open Access This article is licensed under a Creative Commons Attribution 4.0 International License, which permits use, sharing, adaptation, distribution and reproduction in any medium or format, as long as you give appropriate credit to the original author(s) and the source, provide a link to the Creative Commons licence, and indicate if changes were made. The images or other third party material in this article are included in the article's Creative Commons licence, unless indicated otherwise in a credit line to the material. If material is not included in the article's Creative Commons licence and your intended use is not permitted by statutory regulation or exceeds the permitted use, you will need to obtain permission directly from the copyright holder. To view a copy of this licence, visit http://creativecommons.org/licenses/by/4.0/.

\section{References}

1. https://ec.europa.eu/eurostat/statistics-explained/index.php/Overw eight_and_obesity_-_BMI_statistics. Accessed 1 Nov 2020

2. World Health Organization. Obesity and Overweight (2020) http:// www.who.int/news-room/fact-sheets/detail/obesity-and-overw eight. Accessed 1 Nov 2020

3. Lauro R, Sbraccia P, Lenzi A (2021) Italian Obesity Barometer Report. Obesity Monitor, vol 3. IBDO Foundation, Rome

4. Chau EH, Lam D, Wong J, Mokhlesi B, Chung F (2012) Obesity hypoventilation syndrome: a review of epidemiology, pathophysiology, and perioperative considerations. Anesthesiology 117(1):188-205

5. Abumrad NA, Klein S (2010) Update on the pathophysiology of obesity. Curr Opin Clin Nutr Metab Care 13(4):357-358

6. Stevens J, Cai J, Pamuk ER et al (1998) The effect of age on the association between body-mass index and mortality. N Engl J Med 338(1):1-7

7. Haslam DW, James WP (2005) Obesity. Lancet 366(9492):1197-1209

8. Flegal KM, Kit BK, Orpana H, Graubard BI (2013) Association of all-cause mortality with overweight and obesity using standard body mass index categories: a systematic review and metaanalysis. JAMA 309(1):71-82

9. Bamgbade OA, Rutter TW, Nafiu OO, Dorje P (2007) Postoperative complications in obese and nonobese patients. World J Surg 31(3):556-560. https://doi.org/10.1007/s00268-006-0305-0 (discussion 561)

10. Valentijn TM, Galal W, Hoeks SE, van Gestel YR, Verhagen HJ, Stolker RJ (2013) Impact of obesity on postoperative and long-term outcomes in a general surgery population: a retrospective cohort study. World J Surg 37(11):2561-2568. https://doi. org/10.1007/s00268-013-2162-y (Erratum in: World J Surg 2013;37(11):2560)

11. Liou DZ, Berry MF (2018) Thoracic surgery considerations in obese patients. Thorac Surg Clin 28(1):27-41. https://doi.org/10. 1016/j.thorsurg.2017.09.004

12. Attaran S, McShane J, Whittle I, Poullis M, Shackcloth M (2012) A propensity-matched comparison of survival after lung resection in patients with a high versus low body mass index. Eur $\mathbf{J}$ Cardiothorac Surg 42(4):653-658

13 Jagoe RT, Goodship TH, Gibson GJ (2001) Nutritional status of patients undergoing lung cancer operations. Ann Thorac Surg 71:929-935 
14. Ferguson MK, Vigneswaran WT (2008) Changes in patient presentation and outcomes for major lung resection over three decades. Eur J Cardiothorac Surg 33(3):497-501

15. Lim E, Batchelor T, Shackcloth M, Dunning J, McGonigle N, Brush T, Dabner L, Harris R, Mckeon HE, Paramasivan S, Elliott D, Stokes EA, Wordsworth S, Blazeby J, Rogers CA, VIOLET Trialists (2019) Study protocol for VIdeo assisted thoracoscopic lobectomy versus conventional open LobEcTomy for lung cancer, a UK multicentre randomised controlled trial with an internal pilot (the VIOLET study). BMJ Open 9(10):e029507. https://doi.org/ 10.1136/bmjopen-2019-029507

16. Solli P, Bertolaccini L, Droghetti A, Bertani A, Gonfiotti A, Nosotti M, Migliore M, Crisci R, VATS Group I (2018) 2016 annual report from the Italian VATS group. Future Oncol 14(6s):23-28. https://doi.org/10.2217/fon-2017-0423

17. Dindo D, Demartines N, Clavien PA (2004) Classification of surgical complications: a new proposal with evaluation in a cohort of 6336 patients and results of a survey. Ann Surg 240(2):205-213. https://doi.org/10.1097/01.sla.0000133083.54934.ae

18 Guerrera F, Olland A, Ruffini E, Falcoz PE (2019) VATS lobectomy vs. open lobectomy for early-stage lung cancer: an endless question-are we close to a definite answer? J Thorac Dis. 11(12):5616-5618. https://doi.org/10.21037/jtd.2019.12.19

19. Poirier P, Alpert MA, Fleisher LA et al (2009) Cardiovascular evaluation and management of severely obese patients undergoing surgery: a science advisory from the American heart association. Circulation 120(1):86-95

20. Pedoto A (2012) Lung physiology and obesity: anesthetic implications for thoracic procedures. Anesthesiol Res Pract 2012:154208

21. Launer H, Nguyen DV, Cooke DT (2013) National perioperative outcomes of pulmonary lobectomy for cancer in the obese patient: a propensity score matched analysis. J Thorac Cardiovasc Surg 145(5):1312-1318

22. Gurevich-Panigrahi T, Panigrahi S, Wiechec E, Los M (2009) Obesity: pathophysiology and clinical management. Curr Med Chem 16(4):506-521

23. Busetto L, Enzi G, Inelmen EM et al (2005) Obstructive sleep apnea syndrome in morbid obesity: effects of intragastric balloon. Chest 128(2):618-623
24. Montané B, Toosi K, Velez-Cubian FO, Echavarria MF, Thau MR, Patel RA, Rodriguez K, Moodie CC, Garrett JR, Fontaine JP, Toloza EM (2017) Effect of obesity on perioperative outcomes after robotic-assisted pulmonary lobectomy. Surg Innov 24(2):122-132. https://doi.org/10.1177/1553350616687435

25. Thomas PA, Berbis J, Falcoz PE, Le Pimpec-Barthes F, Bernard A, Jougon J, Porte H, Alifano M, Dahan M, EPITHOR Group (2014) National perioperative outcomes of pulmonary lobectomy for cancer: the influence of nutritional status. Eur J Cardiothorac Surg. 45(4):652-659. https://doi.org/10.1093/ejcts/ezt452 (discussion 659)

26. Wang C, Guo M, Zhang N, Wang G (2018) Association of body mass index and outcomes following lobectomy for non-small-cell lung cancer. World J Surg Oncol 16(1):90. https://doi.org/10.1186/ s12957-018-1394-6

27. Paul S, Andrews W, Osakwe NC, Port JL, Lee PC, Stiles BM, Altorki NK (2015) Perioperative outcomes after lung resection in obese patients. Thorac Cardiovasc Surg 63(7):544-550. https:// doi.org/10.1055/s-0034-1383720

28. Tulinský L, Mitták M, Tomášková H, Ostruszka P, Penka I, Ihnát $P$ (2018) Obesity paradox in patients undergoing lung lobectomy—myth or reality? BMC Surg 18(1):61. https://doi.org/10. 1186/s12893-018-0395-2

29. St Julien JB, Aldrich MC, Sheng S et al (2012) Obesity increases operating room time for lobectomy in the society of thoracic surgeons database. Ann Thorac Surg 94(6):1841-1847

30. Childers DK, Allison DB (2010) The 'obesity paradox': a parsimonious explanation for relations among obesity, mortality rate and aging? Int J Obes 34:1231-1238

Publisher's Note Springer Nature remains neutral with regard to jurisdictional claims in published maps and institutional affiliations. 